\title{
ICU Effective Creative Writing Instruction
}

\section{TCU}

Katelyn Crow, Undergraduate Student, Texas Christian University

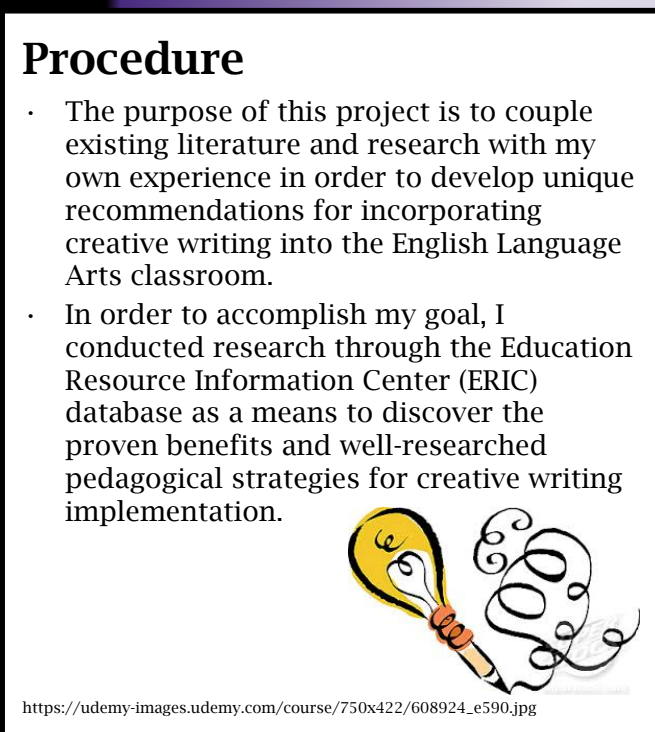

Literature Review

Anae defines the task of creative writing as

"Creatlingl short imaginative and
informative texts that show emerging use

of appropriate text structure, sentence

level grammar, word choice, spelling,
punctuation and appropriate multimoda

punctuation and app
elements" (Anae 125).

Bayat postulates that creative thinking is a

Bayat postulates that creative thinking is
skill that can be taught if teachers are

willing to emphasize process over produ

and foster an environment free of
constraints and risks (Bayat 163 .

Guillén and García Bermejo suggest that

teachers need in-service opportunities to

write and read creatively in order to better

effectively guide their students through
creative writing projects (Guillén \& García

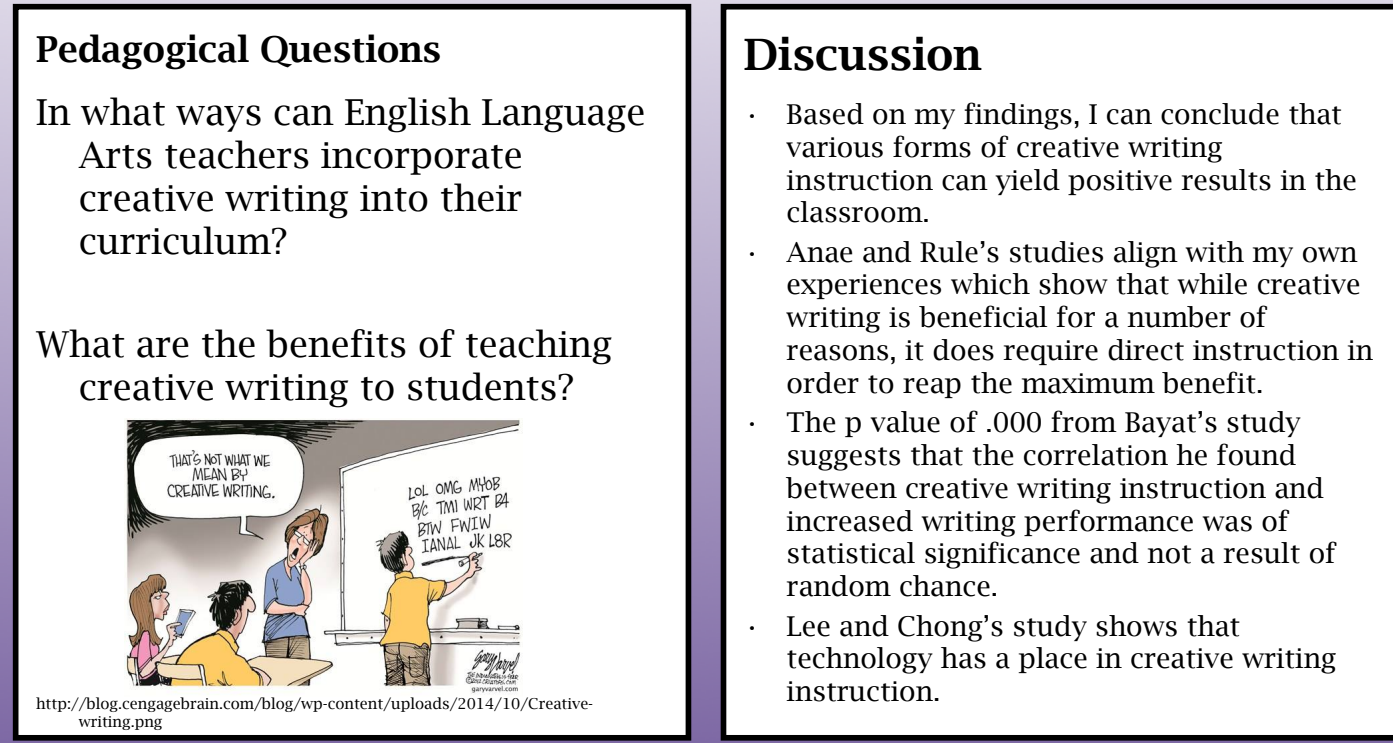

\section{Findings}

- Anae found that "not only did creative writing facilitate social and literacy skills, but provided a

- Rule conducted a practitioner inquiry in which she observed that creative writing prompts alone were not sufficient to get a student's thinking going, but rather teacher assistance was necessary

Bayat conducted creative writing assessments before and after students
writing instruction. The results garnered a p value of .000 (Bayat 623 ).

Lee and Chong used a software prototype called Storyworld to examine the effects of creative after going through the program.

Lee and Chong noted that in the pre-test,

However, in the post-test, the structure

improved drastically which contributed to

better creativity as the story was coh

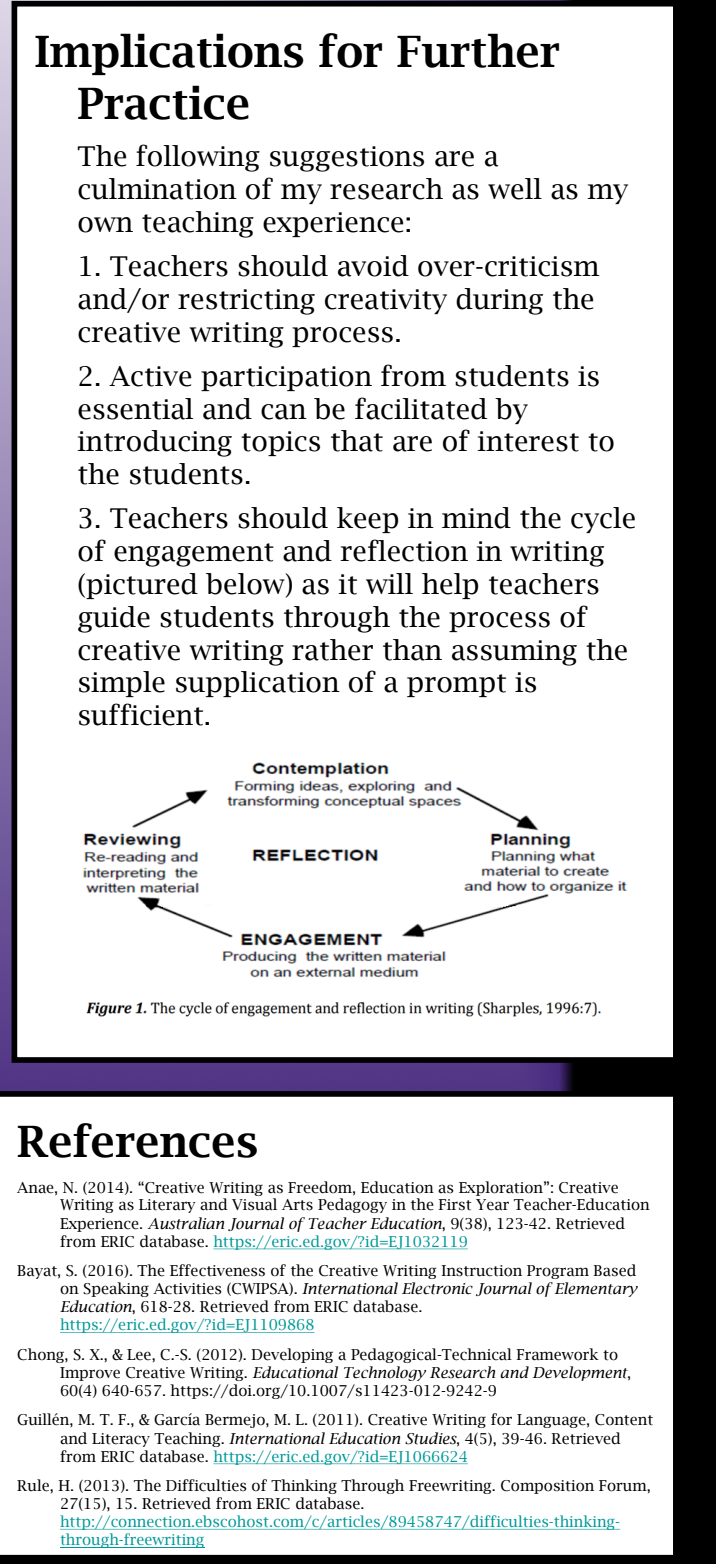

Implications for Further

can be facilitated by

Tende

2017 Boller Review: J UNa 